\title{
A ilha da utopia na Baía de Guanabara: de Vespúcio a Pigafetta
}

The Island of Utopia in Guanabara Bay: From Vespucci to Pigafetta

Paulo Roberto Pereira*

\section{Resumo}

A Terra do Brasil e a literatura de viagens: Vespúcio e as Quatro Navegações ou Lettera a Soderini. Falsa atribuição da descoberta do Rio de Janeiro a Gaspar de Lemos e a André Gonçalves. Fundação da "Feitoria do Rio de Janeiro", chamada "Feitoria de Cabo Frio". A estadia da frota de Magalhães na Guanabara e a prioridade do topônimo "Rio de Janeiro". João Lopes de Carvalho e seu filho Joãozinho "Niñito" na feitoria da Baía de Guanabara. More e a utopia política numa ilha do Rio de Janeiro.

Palavras-chave: Vespúcio; Pigafetta; Rio de Janeiro (Baía de Guanabara); Feitoria do Rio de Janeiro (Cabo Frio); More; Utopia.

\begin{abstract}
The Land of Brazil and travel literature: Vespucci and Quatro Navegações or Lettera a Soderini. False attribution of the discovery of Rio de Janeiro to Gaspar de Lemos and André Gonçalves. Foundation of "Feitoria do Rio de Janeiro", called "Feitoria de Cabo Frio". The stay of the Magellan fleet in Guanabara and the priority of the toponym "Rio de Janeiro". João Lopes de Carvalho and his son Joãozinho "Niñito" at the Guanabara Bay factory. More and political utopia on an island in Rio de Janeiro.

Keywords: Vespucci; Pigafetta; Rio de Janeiro (Guanabara Bay); Cabo Frio Factory (Rio de Janeiro); More; Utopia.
\end{abstract}

\section{Aos meus amigos Antonio Carlos Secchin, Antonio Maura e Paulo Knauss}

A denominada Literatura de Viagens (Finazzi-Agrò, 1993, pp. 394-396; Pereira, 2002, pp. 25-43) teve seu auge durante a expansão europeia das grandes viagens marítimas nos trinta anos que medeiam entre o descobrimento da

\footnotetext{
* Universidade Federal Fluminense (UFF), Niterói, RJ, Brasil. paulorobertopereira08@gmail.com $<$ https://orcid.org/0000-0002-3827-8230>
} 
América por Cristóvão Colombo, em outubro de 1492, e o retorno à Sevilha, em setembro 1522, do navio comandado por Juan Sebastián Elcano. O navegador espanhol completou a primeira volta ao mundo na viagem que buscava a rota pelo ocidente para se chegar às Ilhas das Especiarias, nas Molucas, na frota comandada por Fernão de Magalhães, descobridor do estreito que une o Atlântico ao Pacífico. Nessa passagem decisiva do século XV para o XVI, a Europa se transformou radicalmente, inaugurando a modernidade renascentista globalizada em que a economia, a ciência e as artes sofreram profundas transformações.

O florescimento da literatura de viagens, filha das descobertas marítimas a que a recente invenção da tipografia por Gutenberg dera intensa divulgação, resultou numa escrita exaltadora de locais paradisíacos que revelaram, a Ocidente e a Oriente, um mundo que o maior geógrafo da antiguidade, Cláudio Ptolomeu, não imaginara, permitindo que Luís de Camões profetizasse em Os Lusíadas (1979 [1572], p. 301): "E, se mais mundo houvera, lá chegara." (Fala de Adamastor, canto VII, estância 14).

Era o prenúncio da globalização, por via marítima, que Colombo, Gama, Cabral, Vespúcio, Magalhães e Elcano estavam a realizar, pois as conquistas portuguesas transformaram o Oceano Atlântico num Mare Nostrum, caminho exclusivo do Mare Clausum lusitano para se chegar ao Oriente pela via do Cabo da Boa Esperança, chancelado pelo Tratado de Tordesilhas de 1494; assim como "o oceano Pacífico foi o mar espanhol do século XVI"1 (Prieto, 1984, p. 135) após a viagem inaugural de Magalhães/Elcano. Em consequência, as cidades de Lisboa e Sevilha tornaram-se epicentros do comércio internacional, verdadeiras Wall Streets da primeira metade do século XVI, desbancando o controle do comércio asiático pela via terrestre que fora exercido pelas cidades italianas de Florença, Gênova e, especialmente, Veneza, que mantivera sólida aliança com o Império Bizantino até a tomada de Constantinopla pelos turcos otomanos, em 1453.

A Terra do Brasil, no amanhecer de 1500, a partir da estadia da frota de Pedro Álvares Cabral na Bahia, tornou-se campo fértil para a divulgação na Europa de uma desconhecida região paradisíaca ao sul do Equador. No entanto, parece que a notícia do descobrimento da Terra de Santa Cruz não estava nos planos da Coroa portuguesa, devido ao sucesso das viagens de Vasco da Gama e de Pedro Álvares Cabral ao Oriente, trazendo produtos como especiarias, porcelana e diamantes, como se lê na carta do rei D. Manuel ao papa Alexandre VI, de 28 de agosto de 1499, pois "o negócio das especiarias e drogas 
orientais representava o ramo mais lucrativo do comércio dos séculos XV e XVI." (Baião, 1923, pp. 336-337).

Assim, a Carta de Pero Vaz de Caminha, certidão de nascimento do Brasil, texto primacial da literatura de viagens, permaneceu inédita até ser publicada, pela primeira vez, no século XIX, na cidade do Rio de Janeiro (Pereira, 1999a, pp. 31-66).

A Carta de Caminha foi um dos vários textos sobre as novas regiões encontradas que revelaram ao viajante renascentista de perfil individualista como se constituía a alteridade entre o velho e o novo mundo nascida do encontro, da descoberta ou da invenção do homem americano (O'Gorman, 1984).

O primeiro texto impresso que se refere exclusivamente ao descobrimento do Brasil por Pedro Álvares Cabral é o panfleto anônimo Copia de una littera del Re de Portogallo mãdata al Re de Castella del viaggio \& sucesso de India (Cópia duma carta do Rei de Portugal mandada ao Rei de Castela acerca da viagem e sucesso da Índia), publicado em Roma, e logo a seguir em Milão, no ano de 1505 (Sanz, 1960, pp. 379-418; Pereira, 1999b, pp. 197-219). No entanto, deve-se ao florentino Américo Vespúcio, através das suas cartas e folhetos, a primeira divulgação na Europa da descoberta da Terra do Pau Brasil e da existência de um "Novo Mundo" que nada tinha a ver com a Geografia de Ptolomeu nem com os delírios de Colombo, que morreu acreditando que chegara a Cipango (Japão) e Catai (China) (Colón, 1982).

Conforme desejo de seu patrão florentino, o banqueiro Lorenzo di Pierfrancesco de Médici, Vespúcio foi enviado à Sevilha para participar dos negócios das viagens marítimas, lucrativo empreendimento a que outros banqueiros italianos estavam associados. Em Portugal, a figura de destaque no patrocínio de viagens marítimas era o mercador e armador Fernão de Noronha, desbravador de lucrativos negócios. A Espanha tinha seu grande financista das aventuras marítimas na figura de Cristóbal de Haro, de poderosa família cristã-nova de Burgos que, a partir de Antuérpia, mantinha ramificações financeiras e comerciais com as famílias Fugger e Welser, de banqueiros alemães. Cristóbal de Haro servira e patrocinara expedições portuguesas nos reinados de d. João II e de d. Manuel, mas, ao retornar à pátria, se aproximara de Carlos V e fora, depois da coroa espanhola, o principal organizador e financiador da viagem de Fernão de Magalhães (Lagoa, 1938, p. 193, nota 1 e pp. 234-235; Schorer, 1957, pp. 275355; Albuquerque; Domingues, 1994, pp. 484-485).

Assim, as novas rotas marítimas deslocaram o epicentro comercial para o oceano Atlântico, deixando o mar Mediterrâneo, das poderosas famílias italianas de Florença, Gênova e Veneza, com seus entroncamentos terrestres pela 
Rota da Seda de domínio muçulmano, num segundo plano. Foi a derradeira ação de mudança de rota do comércio com o Oriente que passara de terrestre a marítimo, após a conquista de Constantinopla pelos otomanos, como se Marco Polo, modelo de viajante a imitar, entregasse o bastão a Américo Vespúcio.

Quando, entre 1503/1504, veio a público, em Paris, o folheto Mundus Novus, tornando célebres as cartas de Américo Vespúcio, a Europa tomou conhecimento de um mundo que destronava as concepções religiosas e geográficas vindas da antiguidade. No rastro do sucesso de Mundus Novus, apareceu em italiano outra publicação de Vespúcio: Lettera di Amerigo Vespucci delle isole nuovamente trovate in quattuor suoi viaggi (Carta de Américo Vespúcio sobre as ilhas recentemente achadas, em quatro viagens suas), também chamada de Lettera a Soderini, endereçada ao supremo magistrado de Florença, Piero Soderini, e publicada nessa cidade em 1505/1506 (Aboal Amaro, 1962, pp. 7376). No ano seguinte, 1507 , essa carta descrevendo as quatro viagens foi traduzida para o latim, rebatizada como Quattuor Americi Vesputti navigationes (Quatro Navegações de Américo Vespúcio) e publicada como apêndice no livro Cosmographiae Introductio, de Martin Waldseemüller, em Saint-Dié-des-Vosges, pequena cidade da Lorena. Nesse livro, Waldseemüller batizou o Novo Mundo com o nome de América por atribuir a Américo Vespúcio a descoberta da quarta parte do mundo (Ronsin, 1991; Sanz, 1959).

Isso confirmava que as cartas do "grande florentino Amerigo Vespucci [...] sobre as suas viagens ao Brasil, traduzidas em diferentes idiomas, impressas e reimpressas sucessivamente, constituíam naquela época a literatura sobre a América do Sul mais divulgada na Europa" (Schuller, 1914, p. 15). Então, a partir dessas encantadoras narrativas de viagens abria-se um oceano de negócios com novas rotas que singravam os mares do Oriente e do Ocidente (Vespucci, 1986). Pois, Américo Vespúcio, o futuro Piloto Mayor da Casa de Contratação de Sevilha, vivera numa época de revoluções marítimas, filosóficas, astronômicas e cartográficas da Renascença em que as suas cartas, da mesma maneira que o Elogio da loucura, de Erasmo de Roterdã (1511), e a Utopia, de Thomas More (1516), simbolizavam o ambiente fervilhante de ideias renovadoras das primeiras décadas do século XVI. Dessa maneira, poemas, diários e cartas sobre viagens marítimas, que exigiam sacrifícios acima da resistência humana, foram transformados em metáforas literárias da história pelos escritos de navegadores e aventureiros do limiar da modernidade, como Colombo, Caminha, Vespúcio e Pigafetta.

O Brasil de Américo Vespúcio é o resultado de duas expedições portuguesas: a primeira, de 1501-1502, com três caravelas, e a segunda, de 1503- 
1504, com seis caravelas; ambas enviadas pelo rei Dom Manuel I sob o comando do navegador Gonçalo Coelho (Mota, 1970, pp. 483-491; Serrão, 1971, p. 604; Albuquerque; Domingues, 1994, p. 257), com Américo Vespúcio tendo posição de destaque na frota (Varnhagen, 1956, pp. 82-105; Guedes, 1975a, pp. 223-245). Nas duas últimas cartas vespucianas de As Quatro Navegações encontram-se detalhadas essas expedições. Nelas, o navegador florentino nomeia os acidentes geográficos da costa brasileira, do Cabo de Santo Agostinho à Ilha da Cananéia. Por isso, parece inconcebível que, após a descoberta da documentação que confirma ter sido Gonçalo Coelho o comandante das viagens de 1501-1502 e 1503-1504, divulgadas nas cartas de Américo Vespúcio, ainda se atribua a Gaspar de Lemos o comando da expedição de 1501-1502 ao Brasil, em que ocorreu a descoberta da Baía de Guanabara/Rio de Janeiro. Gaspar de Lemos comandava o navio de mantimentos da frota de Cabral com destino à Índia, mas com o descobrimento do Brasil, retornou a Portugal para dar a notícia ao rei D. Manuel, levando consigo a Carta de Pero Vaz de Caminha. Até agora não se encontrou algum documento que demonstre ter ele alguma vez retornado ao Brasil. O mesmo se dá com o desconhecido André Gonçalves, de quem também nada se sabe, mas que, de longa data, como Gaspar de Lemos, aparece citado como descobridor da Baía de Guanabara/Rio de Janeiro.

Vespúcio, em sua primeira viagem ao Brasil, de 10 de maio de 1501 a 07 de setembro de 1502 - que se encontra em As Quatro Navegações, descrita como "terceira navegação" -, narra, em primeira pessoa, os acidentes geográficos do litoral brasileiro do Nordeste para o Sudeste, a partir da região do atual estado do Rio Grande do Norte. Foi Francisco Adolfo de Varnhagen quem demonstrou que o topônimo "Rio de Janeiro" era uma anomalia diante do padrão adotado pelo navegante Américo Vespúcio que, obediente à data religiosa católica, "com o calendário na mão, foi sucessivamente batizando as diferentes paragens da costa" (Varnhagen, 1956, p. 83) com nomes que invocavam o santo do dia: Cabo de Santo Agostinho, Rio de São Francisco, Baía de Todos os Santos, Angra dos Reis, etc. Como os documentos existentes não oferecem resposta inquestionável sobre a origem desse topônimo, "julgamos que as designações discordantes do sistema, do tipo Cabo Frio e Rio de Janeiro, por exemplo, têm outra paternidade. São nomes dados sem maior intenção, simples pontos de referência da marujada, a relembrar-lhe um cabo inominado que dobraram quando fazia frio; um rio (?) que divisaram ou em que estiveram no mês de janeiro." (Cunha, 2004, p. 204).

Os outros topônimos relacionados à região do Rio de Janeiro pertencem 
à onomástica tupi, como "Guanabara", que significa "enseada de rio ou braço de mar", e "carioca" significando "casa do branco".

Nessa "terceira navegação", a primeira de Vespúcio ao Brasil, narra ele o encontro inicial com o nativo da Terra do Brasil, que não foi amistoso, pois eram canibais, matando um marinheiro que se aventurara a ter contato com eles (Amado; Figueiredo, 2001, p. 335). A viagem prosseguiu batizando-se o Cabo de Santo Agostinho, em Pernambuco; e na costa de Bahia, aconteceu um encontro pacífico com indígenas. Mesmo descrevendo com bastantes detalhes os povos originários, Vespúcio não estava interessado no homem da terra, pois era um navegador que tinha uma missão comercial a cumprir, por isso realçava que a única riqueza encontrada era o pau-brasil.

No folheto Quatro Navegações ou Lettera a Soderini, Vespúcio narra sua segunda viagem ao Brasil, chamada de "quarta navegação", em que participou da frota de seis navios comandada por Gonçalo Coelho, que durou de 10 de maio de 1503 a 4 de setembro de 1504. Nessa viagem, Vespúcio fundou, em novembro de 1503, a feitoria do Rio de Janeiro, que se tornou o primeiro estabelecimento comercial nas Américas abaixo da linha do Equador (Varnhagen, 1956, pp. 89-90). A feitoria para estocar o pau-brasil a ser transportado pelos navios funcionou de 1504 a 1516; e, durante séculos, se discutiu onde Vespúcio a fundara. Finalmente, estudos das últimas décadas confirmaram que a "Feitoria do Rio de Janeiro", também chamada "Feitoria de Cabo Frio", era localizada na Baía de Guanabara, na ilha do Gato ou Paranapuã, atual Ilha do Governador; região sob o domínio dos índios temiminós, chefiados pelo cacique Gato Maracajá, aliado dos portugueses desde a descoberta da Baía de Guanabara/Rio de Janeiro, pacto que se manteve através do seu filho, cacique Araribóia, até a fundação da cidade do Rio de Janeiro (Fernandes, 2002, pp. 103140).

Na Lettera a Soderini, Vespúcio descreve a fundação, na Baía de Guanabara, da "Feitoria de Cabo Frio":

Esperamos naquele porto (baía de Todos os Santos) dois meses e quatro dias. Visto que não chegava nenhuma mensagem, acordamos - a conserva (comboio de navios) e eu - percorrer a costa. Navegamos mais para frente 260 léguas, até que chegamos a um porto (baía de Guanabara) onde acordamos fazer uma fortaleza: e a fizemos. Nela deixamos 24 homens cristãos que a minha conserva trazia e havia recolhido da nau capitânia que se perdera (a nau do comandante Gonçalo Coelho afundara nos arredores da ilha de Fernando de Noronha). 
Naquele porto estivemos cerca de cinco meses, fazendo a fortaleza e carregando os nossos navios de pau-brasil, pois não podíamos ir mais adiante porque não tínhamos gente e me faltavam muitos equipamentos. Feito tudo isso, acordamos em voltar a Portugal, que estava com vento entre grego e tramontano (vento entre norte e nordeste). Deixamos os 24 homens que ficaram na fortaleza com mantimentos para seis meses e com 12 bombardas e muitas outras armas. Pacificamos toda a gente da terra, da qual não se fez menção nessa viagem, não porque não víssemos e praticássemos com infinita gente dela, pois fomos terra adentro, cerca de 30 homens, 40 léguas, onde vi tantas coisas que deixo de contar, reservando-as para as minhas “Quatro Jornadas". Aquela terra está 18 graus fora da linha equinocial da parte austro e 37 graus fora do meridiano de Lisboa, mais a ocidente, segundo mostram os nossos instrumentos.

Feito tudo isso, despedimo-nos dos cristãos e da (gente) da terra e começamos nossa navegação a norte-nordeste, que é vento entre tramontana e grego, com o propósito de ir direto com nossa navegação a esta cidade de Lisboa (Amado; Figueiredo, 2001, p. 346; Vespúcio, 2003, p. 117; Fontana, 1995, p. 179; Souza, 1954, p. 191; Vespucci, 1986, pp. 135 e 136; Ramusio, 1979, pp. 668-669).

Depois da fundação por Vespúcio da "Feitoria de Cabo Frio", na atual ilha do Governador, na Baía de Guanabara, outros navegadores a serviço de Portugal e Espanha estiveram na feitoria para se reabastecerem de alimentos e carregarem o pau-brasil, como o navegante português João de Lisboa, a quem se atribui a descoberta do Rio da Prata em 1514, que esteve carregando pau-brasil na Feitoria do Rio de Janeiro na sua volta à Europa (Bueno, 1998, pp. 119-120).

Em outubro de 1515, o navegador português ou espanhol João Dias de Solís, a serviço da Coroa espanhola, partiu de Sevilha com duas caravelas em direção à América do Sul, na sonhada busca da passagem para o Oceano Pacífico, que desde Cristóvão Colombo atiçava a imaginação dos viajantes que desejavam atingir as Ilhas das Especiarias, no Oriente. Solís chegou ao Rio da Prata em janeiro de 1516, onde morreu em luta com os indígenas. E durante muito tempo o Rio da Prata foi conhecido como Rio Solís. O restante da expedição de Solís de volta à Espanha, sob o comando de Francisco Torres, parou na Feitoria do Rio de Janeiro, recolheu provisões e pau-brasil e resgatou o piloto português João Lopes de Carvalho, que ali fora deixado em 1511 pelo comandante da Nau Bretoa. Mais tarde, João Lopes de Carvalho se tornaria figura de destaque na viagem de Magalhães/Elcano, que circundou a Terra 
pela primeira vez, vindo a morrer em Tidore, uma das ilhas Molucas, em 14 de fevereiro de 1522.

Sob o comando de Fernão de Magalhães, uma frota com cinco navios Trinidad, Victoria, San Antonio, Santiago e Concepción - saiu de Sevilha a 10 de agosto de 1519, partindo do porto de Sanlúcar de Barrameda a 20 de setembro de 1519 com uma tripulação de 237 homens, segundo Pigafetta, embora haja divergência sobre o total de tripulantes embarcados (Garcia, 2007, p. 174). A expedição buscava uma rota a ocidente para "ir a descobrir la Especiería", as Molucas, conforme as Capitulações assinadas a 22 de março de 1518, em Valladolid, entre Magalhães e o rei Carlos V de Espanha. Magalhães procurava descobrir uma passagem na muralha de terra que constituía a América para poder navegar no Oceano Pacífico e, assim, criar uma rota para o Oriente. Depois de passar pelas Ilhas Canárias e costear parte da África ocidental, a frota de Magalhães atravessou o Atlântico e ancorou na Baía de Guanabara no dia 13 de dezembro de 1519, permanecendo no Rio de Janeiro até 27 de dezembro de 1519.

Este acontecimento, que inseriu o Brasil na mais arrojada viagem marítima, consta de uma série de relatos escritos por participantes da viagem, como o diário de "um piloto genovês", atribuído ao italiano Léon Pancaldo, que designa a primeira região americana em que a frota desembarcou em 1519 pelo topônimo de Rio de Janeiro:

Fazendo-se tanto avante como a dita paragem, fez sua rota a demandar o Brasil, e tanto que houveram a vista da outra costa do Brasil, governou ao sudoeste, ao longo dela até o Cabo Frio, que está a 23 graus da banda do sul; e deste cabo governou a loeste obra de 30 léguas; a demandar o Rio de Janeiro, que está em a mesma altura do Cabo Frio; e entraram no dito Rio o dia de Santa Luzia, que era 13 de dezembro, em o qual Rio tomaram lenha e estiveram em ele até a primeira oitava do Natal, que era a 26 de dezembro do mesmo ano (Garcia, 2007, pp. 211212).

Outro documento fundamental que confirma ser o topônimo "Rio de Janeiro" conhecido em 1519 é a carta escrita em Sevilha, em 12 de maio 1521, por Juan López de Rescalde, o qual colheu os depoimentos dos tripulantes da nau San Antonio, que abandonara a esquadra de Magalhães, como explica Rolando A. Laguarda Trías:

Juan López Caravallo havia vivido na Baía de Janeiro, ou seja, no Rio de Janeiro, e ali havia deixado um filho que, em 1519, tinha sete anos de idade, o que equi- 
vale a dizer que havia nascido em 1512. Estes dados permitem identificar o piloto Juan López Caravallo, da armada de Magalhães, com o piloto João Lopes de Carvalho, da Nau Bretoa. Em primeiro lugar, os nomes de ambos, salvo ligeira variante do segundo sobrenome, são os mesmos; em segundo lugar, Lopes de Carvalho foi deixado no Brasil em 1511 e o nascimento do filho em 1512 se ajusta perfeitamente aos dados; em terceiro lugar, os indígenas da Baía de Janeiro o reconheceram e lhe trouxeram a sua mulher e o seu filho; em suma, há perfeita concordância de todos os dados segundo os quais ele, João Lopes de Carvalho, desterrado da Bretoa, é a mesma pessoa que retornou com Magalhães² (Laguarda Trías, 1972, p. 14).

Magalhães, entretanto, ao entrar nas águas da Guanabara, deu à região o nome de "Baía de Santa Luzia", por chegar no dia consagrado à santa católica, em vez de empregar o topônimo Rio de Janeiro, com que a região fora denominada na época de Américo Vespúcio.

O primeiro registro conhecido do nome "Rio de Janeiro" se observa na carta náutica de 1513 do almirante otomano Piri Reis, que se encontra no museu Topkapi Sarayi, em Istambul, baseada em informações oriundas de navegantes portugueses (Guedes, 2001, p. 400). Portanto, o topônimo "Rio de Janeiro" era corrente na cartografia quinhentista quando da chegada da frota de Magalhães à Guanabara em 1519. Lembra o geógrafo Maurício de Almeida Abreu que "Podemos concluir, portanto, que é com o mapa de Piri Reis, e não com a viagem de Fernão de Magalhães, que 'o topônimo Rio de Janeiro entra no mundo da história”' (Abreu, 2010, p. 41).

E "o primeiro mapa a identificar a Baía de Guanabara com o nome de Rio de Janeiro e a representá-la corretamente quanto à situação geográfica” (Teixeira Filho, 1975, p. 15) é a Carta Terra Brasilis, do Atlas Miller, de 1519, feito por Lopo Homem, Pedro Reinel e seu filho Jorge Reinel, que se encontra na Biblioteca Nacional de Paris, em que o topônimo "Rio de Janeiro" está transcrito corretamente (Cortesão; Mota, 1987, pp. 55-61, estampas 16-24). É provável que Magalhães, ao dar novo nome à região da Baía de Guanabara, tentasse se precaver de futuras acusações de que navegara sem autorização em território português, acordado pelo Tratado de Tordesilhas; embora sabendo que a América Portuguesa era conhecida pela difusão que tiveram os escritos de Américo Vespúcio a partir de Mundus Novus, de 1504, e das Quatro Navegações, de 1507.

Magalhães certamente fora informado do nome da baía onde aportara, porque autorizara a conduzir o farol da frota, a partir de Cabo Frio, o piloto da 
nau Concepción João Lopes de Carvalho (Albuquerque; Domingues, 1994, pp. 217-218), que conhecia a navegação no Atlântico Sul. João Lopes de Carvalho passara quatro anos na feitoria da Baía de Guanabara, onde fora deixado em 1511 pelo comandante da Nau Bretoa (Varnhagen, 1956, p. 89), conforme informa o diário da nau: ele era casado, morador em Fangas da Farinha, no bairro da Alfama, em Lisboa e fora nomeado piloto da Nau Bretoa para vir à América Portuguesa buscar pau-brasil na Feitoria do Rio de Janeiro. No final do diário da Nau Bretoa encontra-se a acusação de que Carvalho fora deixado na feitoria pelo comandante da nau, capitão Cristóvão Pires, por participar do roubo de ferramentas de derrubada do pau-brasil (Baião, 1923, pp. 343-347), o que levou o capitão a retornar sem ele para Portugal em 27 de julho de 1511 (Carvalho, 1992, pp. 75-113). O retorno de João Lopes de Carvalho ao Rio de Janeiro confirmava que ele era "um prático experiente nos caminhos do Atlântico Sul. O seu nome ficaria ligado à história do Brasil como um dos primeiros 'moradores' europeus da baía de Guanabara.' (Serrão, 1965, p. 24).

Na sua volta ao Rio de Janeiro na frota de Magalhães, João Lopes de Carvalho encontrou o filho que tivera com uma indígena da Guanabara que veio a ser conhecido na frota de Magalhães como Joãozinho "Niñito". Este brasileirinho da Guanabara participou com o pai da travessia do Estreito de Magalhães e do Oceano Pacífico, sobrevivendo à difícil viagem que singrou pela primeira vez as águas do Oceano Pacífico até chegar às Filipinas. Assim, nessa aventura marítima que iniciou a globalização, pode-se incluir a história de Joãozinho Lopes de Carvalho, o "Niñito", único brasileiro que participou da viagem liderada inicialmente por Fernão de Magalhães, morto pelos nativos na Ilha de Mactán, Filipinas, em 27 de abril de 1521, e concluída por Juan Sebastián Elcano, ao retornar a Sevilha em setembro de 1522. Portanto, a frota de Magalhães ia "levando um brasileirinho de apenas 7 anos, talvez o primeiro marujo da nova e forte raça que portugueses e gentios começavam a produzir" (Guedes, 1975b, p. 377), como um registro precoce da sociedade multiétnica brasileira (Pereira, 2018, pp. 165-177).

O cronista da expedição de Magalhães, Antonio Pigafetta, que pertence à linhagem dos grandes viajantes italianos, como Marco Polo, Cristóvão Colombo e Américo Vespúcio, os quais revelaram ao ocidente os caminhos da integração planetária (San Filippo, 1874), descreveu, entre admirado e condescendente, o seu encontro com os indígenas da ilha do Governador, quando da estadia da frota de Magalhães na "Feitoria de Cabo Frio/Rio de Janeiro", na Baía de Guanabara, de 13 a 27 de dezembro de 1519: 
Até que chegamos a uma terra chamada Terra do Brasil ${ }^{3}$, a 23 graus de latitude sul, que se prolonga desde o Cabo de Santo Agostinho, que fica a oito graus da mesma latitude. Ali nos abastecemos de galinhas, batatas, abacaxi muito doce, que é, na verdade, uma fruta deliciosa ${ }^{4}$; carne de anta, parecida com a da vaca ${ }^{5}$; cana de açúcar ${ }^{6}$ e uma infinidade de coisas que omito para não ser prolixo.

Entramos nesse porto ${ }^{7}$ no dia de Santa Luzia ${ }^{8}$ e, nesse dia, o sol estava no zênite, fazendo mais calor do que quando passamos pela linha do Equador.

Esta Terra do Brasil é abundante e maior que Espanha, França e Itália juntas. Pertence ao rei de Portugal. Os habitantes desta terra não são cristãos nem adoram coisa alguma. São regidos pelos costumes da natureza e vivem cento e vinte cinco anos e, às vezes, até cento e quarenta anos ${ }^{9}$.

Possuem embarcações, chamadas canoas, feitas de um só tronco de árvore cortado e escavado com machado de pedra. Eles trabalham com a pedra como fazemos com o ferro, que desconhecem. Cada canoa comporta de trinta a quarenta homens. Remam com pás parecidas com as usadas em nossos fornos e, por serem tão escuros, irem desnudos e desprovidos de pelos que lhes cubram, e completamente nus, assemelham-se, quando remam, àqueles da Lagoa Estígia ${ }^{10}$.

Os homens e as mulheres não têm nada diferente de nós. Comem a carne de seus inimigos; não porque seja boa, senão por costume.

Não a comem de imediato, mas cada um corta um pedaço e o leva à sua casa e o defuma. Depois, a cada oito dias, corta um pedaço e o come misturado com outros alimentos em memória dos seus inimigos. Isto foi o que me contou João Lopes de Carvalho ${ }^{11}$, o piloto que veio conosco e que havia passado quatro anos nesta terra. Este povo tatua todo o corpo e o rosto de forma maravilhosa; de diversas maneiras, inclusive as mulheres. Eles depilam todo o cabelo do corpo, retirando inclusive a barba $^{12}$.

Quase todo homem, exceto mulheres e crianças, tem, no lábio inferior, três perfurações, onde colocam pedras cilíndricas largas como um dedo, que pendem do lábio ${ }^{13}$. Eles não são negros, mas têm cor de alabastro. Levam suas genitálias descobertas. Seus corpos não têm pelos, e assim, tanto homens quanto mulheres sempre estão nus. Seu rei é chamado de cacique.

Fazem um pão redondo e branco com medula de árvore - não é muito bom -, que nasce entre a árvore e a sua casca, e é como a ricota ${ }^{14}$.

Rezou-se missa duas vezes em terra e com grande prazer os vimos ajoelharem-se em penitência, com as mãos juntas. Seriam convertidos com facilidade à fé de Jesus Cristo.

Um dia uma bela jovem subiu à nau capitânia em que eu estava buscando conseguir alguma lembrança. Dirigiu-se, então, para o camarote do mestre da embarcação 
e encontrou um cravo mais largo que um dedo. Com grande destreza e galanteria o introduziu entre os lábios dos seus órgãos genitais. E, rapidamente, ante a admiração dos meus olhos e dos do capitão-general, desceu do barco.

Alguns vocábulos deste povo do Brasil ${ }^{15}$.

Milho = Maíz

Farinha $=$ Hui

Anzol $=$ Pinda

Faca $=$ Tacse

Pente $=$ Chipag

Tesoura $=$ Pirame

Chocalho $=$ Itanmaraca

Bem, melhor $=$ Tum, maragatum ${ }^{16}$

(Pigafetta, 1998, pp. 98-100; Alba, 2012, pp. 197-202; Pigafetta, 1923, pp. 42-49;

Pigafetta, 1969, pp. 42-45; Pigafetta, 1999, pp. 168-175; Castro, 2010, pp. 89-94).

Lembra Rubens Borba de Moraes que o Diário de Pigafetta é obra de grande valor para o Brasil, porque descreve os povos originários do Rio de Janeiro no relato da viagem e, no final, lista um vocabulário de oito palavras tupis. Foi a primeira vez que palavras tupis apareceram impressas (na verdade, bastante deformadas) (Moraes, 2010, p. 195), o que confirma ser o relato de Pigafetta a primeira descrição antropológica dos tupinambás da região da Baía de Guanabara.

A extraordinária aventura vivida por Vespúcio em 1503, e por Pigafetta em 1519, com os temiminós do Rio de Janeiro, só teria comparação algumas décadas mais tarde, quando outros letrados europeus - André Thevet, Jean de Léry, Hans Staden, Manuel da Nóbrega, José de Anchieta -, que beberam, por diferentes vias, nas águas do humanismo renascentista, relataram suas experiências com os indígenas da Baía de Guanabara.

Inspirado pelas cartas de Vespúcio, Thomas More criou sua fábula Utopia na Baía de Guanabara, ao colocar na "Feitoria de Cabo Frio/Rio de Janeiro" seu herói Rafael Hitlodeu, que, imbuído de espírito aventureiro, "português que era, pela vontade de conhecer o orbe terrestre, juntou-se a Américo Vespúcio em três de suas quatro últimas navegações, cujos relatos são lidos pelo mundo" (More, 2017, p. 29). Assim, por mistificação filosófico-literária, More, utilizando-se do resgate dos ideais de felicidade da filosofia clássica postos em circulação pelo Renascimento, antecipou-se aos letrados que vivenciaram a realidade quinhentista da Baía de Guanabara e construiu uma utopia política numa 
ilha do Rio de Janeiro, antecipando-se à cidade ideal dos trópicos sonhada por portugueses e franceses.

Assim, os escritos sobre a Feitoria do Rio de Janeiro/Cabo Frio legados por Vespúcio e Pigafetta oferecem a oportunidade para se reafirmar que Antonio Pigafetta "era um homem cultivado que respirou os valores do humanismo" (Firpo, 1987, p. 15). Característica também encontrada em Américo Vespúcio, filho da Florença renascentista em cujas narrativas de viagens, reveladoras de novos mundos e novos saberes, se encontram as influências determinantes do humanismo italiano do alvorecer da Renascença. Desse modo, Vespúcio e Pigafetta, humanistas da Renascença que transitaram pelos caminhos da aventura marítima impulsionada pelas novas redes comerciais planetárias, deixaram seus testemunhos sobre o encontro inaugural numa ilha da Baía de Guanabara, onde a utopia se fizera presente pela convivência pacífica e pela ausência de propriedade que caracterizava o cotidiano dos indígenas daquela região paradisíaca, confirmando que a motivação primeira, a econômica, inseriu a Terra do Brasil não só no comércio internacional, mas, o que é decisivo, na história das ideias do século XVI.

\section{REFERÊNCIAS}

ABOAL AMARO, José Alberto. Amerigho Vespucci: ensayo de bibliografía crítica. Madrid: Libreria para Bibliófilos, 1962.

ABREU, Maurício de Almeida. Geografia histórica do Rio de Janeiro (1502-1700). Vol. 1. Rio de Janeiro: Andrea Jakobsson, 2010.

ALBA, Ramón (Ed.). La primera vuelta al mundo. Segunda edición. Madrid: Miraguano; Polifemo, 2012.

ALBUQUERQUE, Luís de (Dir.); DOMINGUES, Francisco Contente (Coord.). Dicionário de história dos descobrimentos portugueses. Vol. 1. Lisboa: Caminho, 1994.

AMADO, Janaína; FIGUEIREDO, Luiz Carlos. Brasil 1500: quarenta documentos. Brasília: Editora Universidade de Brasília; São Paulo: Imprensa Oficial do Estado de São Paulo, 2001.

BAIÃO, António. O comércio do pau-brasil. In: DIAS, Carlos Malheiro (Dir.). História da colonização portuguesa do Brasil. Vol. II. Porto: Litografia Nacional, 1923. pp. 336-347.

BUENO, Eduardo. Náufragos, traficantes e degredados: as primeiras expedições ao Brasil, 1500-1531. Rio de Janeiro: Objetiva, 1998.

CAMÕES, Luís de. Os lusíadas. Edição de António José Saraiva. Porto: Figueirinhas; Rio de Janeiro: Padrão, 1979 [1572]. 
CASTRO, Xavier de (Ed.); HAMON, Jocelyne; THOMAZ, Luís Filipe (Colab.). Le voyage de Magellan (1519-1522). La relation d'Antonio Pigafetta \& autres témoignages. 2e Édition remaniée. Paris: Chandeigne, 2010. pp. 89-94.

CARVALHO, Filipe Nunes de. Desvendamento e guarda da costa do Brasil pelos portugueses (1501-1533). In: JOHNSON, Harold; SILVA, Maria Beatriz Nizza da (Coord. e colab.). Nova história da expansão portuguesa. O império luso-brasileiro (1500-1620). Lisboa: Estampa, 1992. pp. 75-113.

COLÓN, Cristóbal. Textos y documentos completos. Edición Consuelo Varela. Madrid: Alianza, 1982.

CORTESÃO, Armando; MOTA, Avelino Teixeira da. Portvgaliae monvmenta cartographica. Reprodução fac-similada. Apresentação Alfredo Pinheiro Marques. Vol. 1. Lisboa: Imprensa Nacional-Casa da Moeda, 1987. pp. 55-61.

CUNHA, Celso. Rio de Janeiro (Para a história de um topônimo). In: CUNHA, Celso. Sob a pele das palavras: dispersos. Cilene da Cunha Pereira (Org.). Rio de Janeiro: Academia Brasileira de Letras; Nova Fronteira, 2004. p. 204.

FERNANDES, Fernando Lourenço. A feitoria da ilha do Gato. In: BUENO, Eduardo (Org.). Pau-brasil. São Paulo: Axis Mundi, 2002. pp. 103-140.

FINAZZI-AGRÒ, Etorre. Literatura de viagens. In: LANCIANI, Giulia; TAVANI, Giuseppe (Coords.). Dicionário da literatura medieval galega e portuguesa. Lisboa: Caminho, 1993. pp. 394-396.

FIRPO, Luigi. [Introduzione]. In: PIGAFETTA, Antonio. Viaggio attorno al mondo. A cura di Mariarosa Masoero. Introduzione di Luigi Firpo. Rovereto: Longo, 1987.

FONTANA, Riccardo. O Brasil de Américo Vespúcio. Tradução de Edilson Alkmim Cunha e João Pedro Mendes. Brasília: UNB; Linha Gráfica, 1995.

GARCIA, José Manuel. A viagem de Fernão de Magalhães e os portugueses. Lisboa: Presença, 2007.

GUEDES, Max Justo. As expedições portuguesas e o reconhecimento do litoral brasileiro. In: História naval brasileira. Vol. I. T. 1. Rio de Janeiro: Ministério da Marinha; Serviço de Documentação Geral da Marinha, 1975a. pp. 223-245.

GUEDES, Max Justo. 500 anos de Brasil na Biblioteca Nacional: a cartografia. In: PEREIRA, Paulo Roberto (Org.). Brasiliana da Biblioteca Nacional: guia das fontes sobre o Brasil. Rio de Janeiro: Nova Fronteira, 2001.

GUEDES, Max Justo. A armada de Fernão de Magalhães e o Brasil. In: MOTA, A. Teixeira da (Org.). A viagem de Fernão de Magalhães e a questão das Molucas: actas do II Colóquio Luso-Espanhol de História Ultramarina. Lisboa: Junta de Investigações Científicas do Ultramar, 1975b.

LAGOA, Visconde de. Fernão de Magalhães. Vol. 1. Lisboa: Seara Nova, 1938.

LAGUARDA TRÍAS, Rolando. Rio de Janeiro: historia de sus denominaciones. Separata da Revista de Ciências do Homem, v. IV, série A. Moçambique, Lourenço Marques: Universidade de Lourenço Marques, 1972. 
MORAES, Rubens Borba de. Bibliographia brasiliana. Tomo II. São Paulo: EDUSP, 2010.

MORE, Thomas. Utopia. Tradução Márcio Meirelles Gouvêa Júnior. Belo Horizonte: Autêntica Editora, 2017.

MOTA, Avelino Teixeira da. Novos documentos sobre uma expedição de Gonçalo Coelho ao Brasil, entre 1503 e 1505. Revista do Instituto Histórico e Geográfico Brasileiro, Rio de Janeiro, v. 287, pp. 483-491, 1970.

O’GORMAN, Edmundo. La invención de América. México: Fondo de Cultura Económica, 1984.

PEREIRA, Paulo Roberto (Org.). Os três únicos testemunhos do descobrimento do Brasil: Carta de Pero Vaz de Caminha, Carta de Mestre João Faras e Relação do Piloto Anônimo. 2a Ed. Rio de Janeiro: Lacerda, 1999a.

PEREIRA, Paulo Roberto. A difusão da viagem de Cabral na Europa quinhentista. In: GRUPIONI, Luís Donisete Benzi (Org.). A carta de Pero Vaz de Caminha: documentos e ensaios sobre o achamento do Brasil. Rio de Janeiro: Xerox do Brasil, 2000, 1999b. pp. 197-219.

PEREIRA, Paulo Roberto. O Brasil dos Viajantes/Viajantes do século XVI. In: PEREIRA, Paulo Roberto (Org.). Brasiliana da Biblioteca Nacional: guia das fontes sobre o Brasil. Rio de Janeiro: Nova Fronteira, 2001. pp. 25-43.

PEREIRA, Paulo Roberto. Brasil en la ruta de la primera vuelta al mundo: la estancia de la flota de Magallanes en Río de Janeiro. In: MARTÍNEZ SHAW, Carlos (Org.). Actas del Congreso Internacional de Historia Primus Circumdedisti me. Madrid: Ministerio de Defensa, 2018. pp. 165-177.

PIGAFETTA, Antonio. Relation du premier voyage autour du monde par Magellan: 1519-1522. Édition du texte français d'après les manuscrits de Paris et de Cheltenham par J. Denucé. Anvers: Janssens; Paris: Ernest Leroux, 1923.

PIGAFETTA, Antonio. Magellan's Voyage. A Narrative Account of the First Circumnavigation. Translated and edited by R. A. Skelton. Vol. 1. New Haven and London: Yale University Press, 1969.

PIGAFETTA, Antonio. Noticia del primer viaje en torno al mundo. Edición italiana con estudio biográfico y literario, Mario Pozzi, 1994. 2 Vols. Vol. II. Traducción al castellano del manuscrito y el estudio, Ana García Herráez. Valencia: Grial, 1998.

PIGAFETTA, Antonio. Relazione del primo viaggio attorno al mondo. Testo critico e commento di Andrea Canova. Presentazione Luciano Formisano. Padova: Antenore, 1999.

PRIETO, Carlos. El Océano Pacífico: navegantes españoles del siglo XVI. Tercera edición. Madrid: Alianza, 1984.

RAMUSIO, Giovanni Battista. Navigazioni e viaggi. A cura di Marica Milanesi. Volume primo. Torino: Einaudi, 1979. 
RONSIN, Albert. La fortune d'un nom: America. Le baptême du Nouveau Monde à Saint-Dié-des-Vosges. Grenoble: Jérôme Millon, 1991.

SAN FILIPPO, Pietro Amat di. Bibliografia dei viaggiatori italiani. Roma: Coi Tipi del Salviucci, 1874.

SANZ, Carlos. El nombre América: libros y mapas que lo impusieron. Madrid: Librería General Victoriano Suárez, 1959.

SANZ, Carlos. Biblioteca Americana Vetustíssima. Ultimas adiciones. Volumen primero (hasta 1507). Madrid: Libreria General Victoriano Suarez, 1960.

SCHORER, Maria Thereza. Notas para o estudo das relações dos banqueiros alemães com o empreendimento colonial dos países ibéricos na América no século XVI. Revista de História, São Paulo, v. 15, n. 32, pp. 275-355, 1957.

SCHULLER, Rodolpho R. A Nova Gazeta da Terra do Brasil (Newen Zeytung auss Presillg Landt) e sua origem mais provável. Rio de Janeiro: Biblioteca Nacional, 1914. SERRÃO, Joaquim Veríssimo. O Rio de Janeiro no século XVI. Vol. 1. Lisboa: Comissão Nacional das Comemorações do IV Centenário do Rio de Janeiro, 1965.

SERRÃO, Joel (Dir.). Dicionário de história de Portugal. Vol. 1. Lisboa: Iniciativas Editoriais, 1971.

SOUZA, T. O. Marcondes de. Amerigo Vespucci e suas viagens. $2^{\text {a }}$ Ed. São Paulo: Instituto Cultural Ítalo-Brasileiro, 1954.

TEIXEIRA FILHO, Álvaro. Roteiro cartográfico da Baía de Guanabara e cidade do Rio de Janeiro - séculos XVI e XVII. Rio de Janeiro: Livraria São José, 1975.

VARNHAGEN, Francisco Adolfo de. História geral do Brasil antes da sua separação e independência de Portugal. Revisão, notas e comentários de Capistrano de Abreu e Rodolfo Garcia. Tomo primeiro. 6a Ed. São Paulo: Melhoramentos, 1956.

VESPUCCI, Amerigo. Cartas de viaje. Introducción y notas de Luciano Formisano. Traductor Ana Maria R. de Aznar. Madrid: Alianza, 1986.

VESPÚCIO, Américo. Novo Mundo: as cartas que batizaram a América. Introdução e notas de Eduardo Bueno. São Paulo: Planeta, 2003.

\section{NOTAS}

${ }^{1}$ Do original: "el océano Pacífico fue el mar español del siglo XVI".

${ }^{2}$ No original: "Juan López Caraballo había vivido em la baya de Henero, o sea, en Rio de Janeiro y ali había dejado un hijo que em 1519 tenía siete años de edad, lo que equivale a decir que había nacido em 1512. Estos datos permiten identificar al piloto Juan López Caravallo de la armada de Magallanes con el piloto Juan Lopes de Carvalho de la nave Bretona. Em primer lugar, los nombre de ambos, salvo ligera variante del segundo apelido, son los mismos; em segundo término, Lopes de Carvalho fue dejado en el Brasil en 1511 y el nacimiento del hijo em 1512 se ajusta perfectamente a los datos; en tercer lugar, los indíge- 
nas de la baya de Henero lo reconocieron y le trajeron a su mujer y a su hijo; em suma, hay perfecta concordância de todos los datos em que ele Juan Lopes de Carvalho, desterrado de la Bretona es la misma persona que volvió con Magallanes..

${ }^{3}$ Notas ao texto de Pigafetta: Brasil ou Verzin. É como os italianos chamaram a madeira Caesalpinia Sappan, nativa na Índia e no Malabar, usada para tingir de vermelho tecidos de algodão. O nome Brasil, que suplantou o de Santa Cruz, foi devido à madeira cor de brasa, outra espécie de Caesalpinia encontrada na terra pelos navegantes.

${ }^{4}$ Abacaxi ou ananás, fruta nativa do Brasil. Os espanhóis a chamaram de piña de América.

${ }^{5} \mathrm{~A}$ anta, ou o tapir, é como um porco grande.

${ }^{6}$ Certamente cana-de-açúcar plantada na feitoria construída por Américo Vespúcio.

${ }^{7}$ É a Baía de Guanabara descoberta por Américo Vespúcio. A região recebeu o nome de Rio de Janeiro porque chegaram a primeiro de janeiro de 1502.

${ }^{8} 13$ de dezembro de 1519 .

${ }^{9}$ A maioria dos viajantes que tiveram contato com indígenas brasileiros nas primeiras décadas do século XVI, como Caminha, Vespúcio e Léry, ressaltaram a hipotética longevidade dos selvagens.

${ }^{10}$ Segundo a mitologia grega, na Arcádia a lagoa Estige, de águas sombrias e putrefatas, formava um rio que desembocava nos Infernos.

${ }^{11}$ Trata-se de João Lopes de Carvalho, piloto da nau "Concepción", que conduziu a nau capitânia de Magalhães até a Baía de Guanabara.

${ }^{12}$ Utilizavam conchas bivalves para depilar o corpo.

${ }^{13}$ É o chamado botoque, adorno feito de madeira ou pedra que os índios colocam no lábio inferior e nas orelhas.

${ }^{14}$ É, provavelmente, o aipim ou a mandioca, planta nativa do Brasil largamente utilizada pelos indígenas.

${ }^{15}$ A transcrição das palavras em tupi por Pigafetta está deformada.

16 "No original: Hasta que llegamos a una tierra llamada la Tierra del Brasil, a 23 grados de latitud sur, que se extiende desde el Cabo de San Agustín, el cual se encuentra situado a 8 grados de latitud sur. Allí tomamos provisiones de gallinas, batatas, piña muy dulce, que es en verdad una fruta deliciosa; carne de anta, que es como la de vaca; caña de azúcar e infinidad de cosas que no enumero por no ser prolijo.

Entramos en ese puerto el día de Santa Lucía y ese día el sol lució dando más calor que cuando estábamos bajo el ecuador.

Esta tierra del Brasil es muy abundante y más grande que España, Francia e Italia juntas: es del rey de Portugal. Las gentes de esta tierra no son cristianas y no adoran cosa alguna; se rigen por las costumbres de la naturaleza y viven ciento veinticinco y hasta ciento cuarenta años. Tienen unas embarcaciones llamadas canoas de un solo mástil formado por el tronco de un árbol cortado y ahuecado y tallado con hachas de piedra. Estas gentes trabajan la piedra 
como nosotros hacemos con el hierro, pero carecen de él. Van treinta o cuarenta hombres en cada una de ellas. Reman con palos como los de horno y al ser tan negros, ir desnudos y sin pelo que les cubra, se parecen cuando reman a aquellos de la Laguna Estigia.

Hombres y mujeres son como nosotros. Comen la carne de sus enemigos, no porque sea buena, sino por cierta costumbre.

No se los comen de inmediato, sino que cada uno corta un pedazo y se lo lleva a su casa y lo ahuma; después, cada 8 días corta un trozo y lo come mezclado con otras cosas en memoria de sus enemigos. Esto es lo que me contó Juan Carvallo, el piloto que venía con nosotros y que había pasado en esta tierra cuatro años.

Esta gente se tatúa de forma maravillosa todo el cuerpo y el rostro de diversas maneras, incluso las mujeres. No les cubre pelo alguno ni tienen barba, porque se la cortan

Casi todos los hombres, excepto mujeres y niños, tienen tres agujeros en el labio inferior, donde llevan piedras cilindricas y tan largas como un dedo, más o menos, que les penden del labio. No son negros del todo, sino de color alabastro. Llevan al descubierto sus genitales. Su cuerpo no tiene pelo, y así, tanto hombres como mujeres van siempre desnudos. A su rey lo llaman cacich.

Hacen un pan redondo y blanco con médula de árbol, no muy bueno, que nace entre éste y su corteza y que es como la ricota.

Se ofició misa dos veces en tierra y con gran placer los veíamos arrodillarse en penitencia, alzando las manos juntas. Se convertirían con facilidad a la fe de Jesucristo.

Un día vino una bella joven a la nave capitana, en la que yo estaba, sólo para conseguir algo que llevarse. Mientras se encontraba esperando allí, dirigió sus ojos hacia el camarote del maestre y vio un clavo más largo que un dedo, con el cual, con gran destreza y galantería, se atravesó los labios de sus genitales de parte a parte; y, rápidamente, bajó del barco, ante mis ojos y los del capitán general.

Algunos vocablos de este pueblo del Brasil:

Al mijo = maíz

Al harina $=$ hui

$\mathrm{Al}$ anzuelo $=$ pinda

Al cuchillo $=$ tacse

Al peine $=$ chigap

A las tijeras $=$ pirame

$\mathrm{Al}$ sonajero $=$ itanmaraca

Bueno, mejor = tum, maragatum"

Artigo submetido em 4 de maio de 2021.

Aprovado em 2 de novembro de 2021.

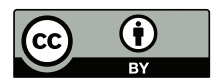

